\title{
Genetics of Primary Inherited Disorders of the Optic Nerve: Clinical Applications
}

\author{
Keri F. Allen, Eric D. Gaier, and Janey L. Wiggs \\ Harvard Medical School, Massachusetts Eye and Ear Infirmary, Boston, Massachusetts 02114 \\ Correspondence: janey_wiggs@meei.harvard.edu
}

Inherited disorders of the optic nerve significantly impact vision in children and adults. The optic nerve disorders most commonly encountered clinically are glaucoma and primary optic neuropathy including Leber's hereditary optic neuropathy (LHON) and autosomal dominant or Kjer's optic atrophy. Current knowledge of the genetics of optic neuropathy and glaucoma makes it possible to test for mutations in disease-causing genes allowing for presymptomatic testing and risk assessment, and recent advances have revealed important disease mechanisms that may suggest potential therapeutic targets. In this perspective, we describe the current approaches and limitations to genetic testing for these disorders and provide an update on the development of gene-based therapies.

nherited diseases of the optic nerve, including glaucoma and optic neuropathy, are important causes of blindness in children and adults. The inherited optic neuropathies most frequently encountered clinically are Leber's hereditary optic neuropathy (LHON) and autosomal dominant (or Kjer) optic neuropathy (Neuhann and Rautenstrauss 2013).

Glaucoma is a complex disorder that includes neurodegeneration of the optic nerve as a defining clinical feature. Elevated intraocular pressure (IOP) is an important risk factor for glaucomatous optic nerve degeneration, however, $\sim 33 \%$ of affected individuals have normal tension glaucoma (NTG) defined by progressive retinal ganglion cell loss despite IOP measurements in the normal range $(<21 \mathrm{mmHg}$ ) (Fan and Wiggs 2010). Phenotypically, NTG can share clinical features with the inherited optic neuropathies. Glaucoma with onset before age 40 (early-onset) can be inherited as Mendelian autosomal recessive or autosomal dominant traits, whereas adult onset disease has complex inheritance (Wang and Wiggs 2014).

Current knowledge of the genetics of optic neuropathy and glaucoma makes it possible to test for mutations in disease-causing genes allowing for presymptomatic testing and risk assessment. Recent advances have revealed important disease mechanisms that may suggest potential therapeutic targets. In this perspective, we review the current recommendations, approaches, and limitations of genetic testing for glaucoma and optic neuropathy, and summarize progress toward novel gene-based and neuroprotective therapies.

Editors: Eric A. Pierce, Richard H. Masland, and Joan W. Miller

Additional Perspectives on Retinal Disorders: Genetic Approaches to Diagnosis and Treatment available at

www.perspectivesinmedicine.org

Copyright (C) 2015 Cold Spring Harbor Laboratory Press; all rights reserved; doi: 10.1101/cshperspect.a017277

Cite this article as Cold Spring Harb Perspect Med 2015;5:a017277 
K.F. Allen et al.

\section{GENETIC TESTING FOR GLAUCOMA}

For many glaucoma patients reducing IOP through medical or surgical treatment can slow disease progression. Genetic testing can identify patients at risk for glaucoma so that presymptomatic surveillance and treatment plans can be developed. Currently, glaucoma genetic testing is most beneficial for patients with disease onset before age 40 (early-onset glaucoma). Mutations causing early-onset glaucoma are rare and have large biological effects, whereas DNA variants contributing to adult-onset glaucoma are common and individually have small effects (Fig. 1). Types of early-onset glaucoma caused by rare mutations with large effects are congenital glaucoma, developmental glaucoma, juvenile open-angle glaucoma, and familial normal tension glaucoma. Common variants with small individual effect sizes contribute to adult-onset primary open angle glaucoma, angle closure glaucoma, and exfoliation glaucoma.

\section{Early-Onset Glaucoma Genetic Testing}

Eight genes are currently known to cause earlyonset (before age 40) glaucoma with autosomal recessive (AR) or autosomal dominant $(A D)$ inheritance (Wang and Wiggs 2014). Approximately $20 \%$ of patients ascertained with earlyonset glaucoma through tertiary care facilities will have mutations in one of the genes known to cause early-onset glaucoma (Fig. 2) (Sena et al. 2004; Lim et al. 2013). Of these, mutations in FOXC1 are most common followed by MYOC, CYP1B1, PAX6, and PITX2. Mutations are rarely identified in OPTN, TBK1 or LTBP2, even in the tertiary care setting (Hauser et al. 2006; Huang et al. 2014; Ritch et al. 2014). Although the overall clinical sensitivity for genetic testing for this group of genes is $\sim 20 \%$, testing for disease-causing mutations in patients and family members has several important benefits including: informed genetic counseling; presymptomatic risk assessment; and development of appropriate treatment and surveillance plans. Each of these will be discussed in the sections below.

\section{Informed Genetic Counseling}

Mutations in early-onset glaucoma genes can cause AD or AR disease: CYP1B1 and LTBP2 cause AR disease, whereas mutations in FOXC1, PITX2, PAX6, MYOC, and OPTN all cause glaucoma inherited as a dominant trait (Wang and Wiggs 2014). Phenotypically, disease caused by mutations in these genes can have similar clinical features making it difficult to make a genetic diagnosis by clinical examination alone. For example, patients with CYP1B1 mutations can present with severe glaucoma that develops during the first three years of life (congenital glaucoma); however, recent studies have shown that some CYP1B1 mutations cause disease that is not clinically evident until the second decade of life ( juvenile glaucoma) (Abu-Amero et al. 2013; Millá et al. 2013). The

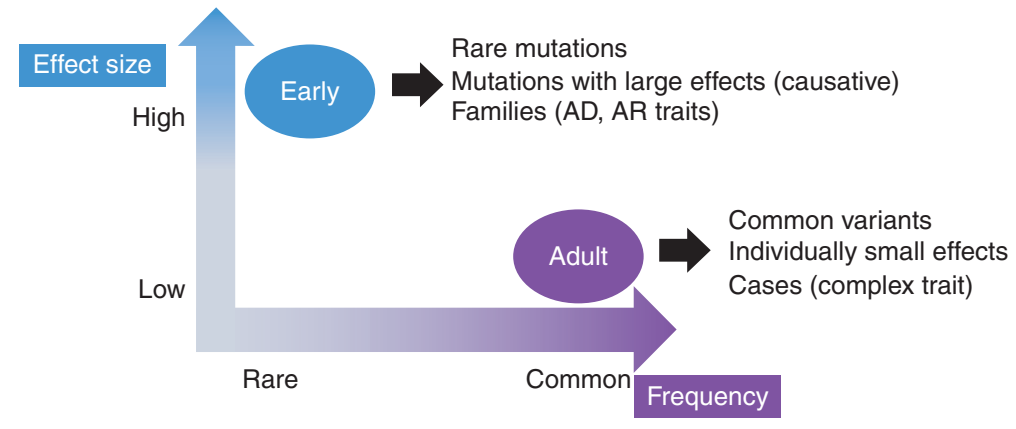

Figure 1. Characteristics of mutations causing early-onset glaucoma compared with genetic variants associated with adult-onset glaucoma. The frequency of the variant is listed on the $\mathrm{x}$-axis and the magnitude of the biological effect (i.e., odds ratio or relative risk) is represented by the values on the $y$-axis. 


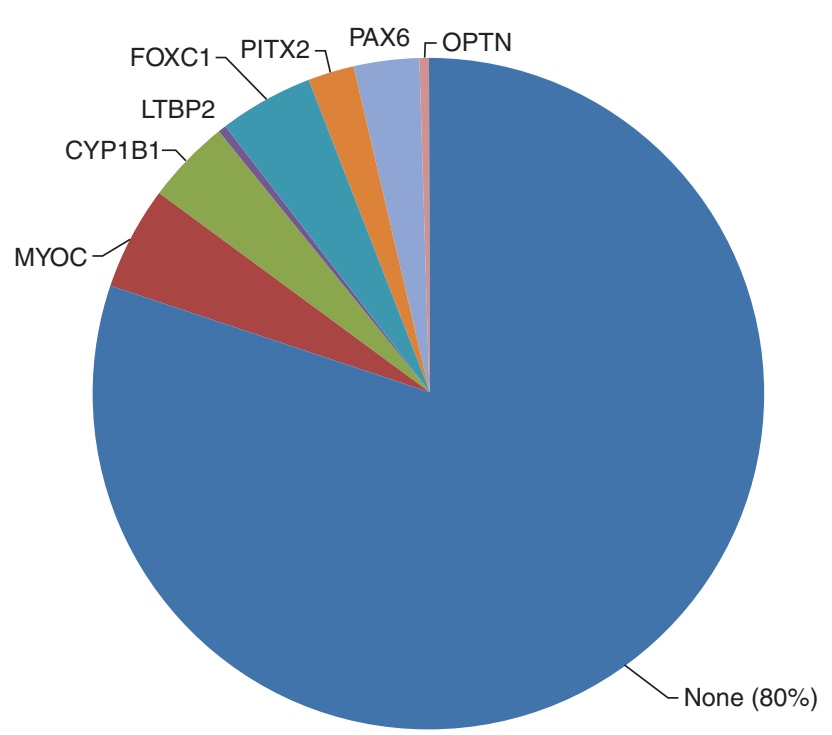

Figure 2. Distribution of mutations in early-onset glaucoma genes in a cohort of glaucoma patients with onset before age 40. Mutations in early-onset glaucoma genes are presented as a fraction of 220 patients evaluated through the genetic testing service at the Massachusetts Eye and Ear Infirmary. Eighty percent of patients with early-onset glaucoma do not have a mutation in a known gene.

CYP1B1-related juvenile glaucoma is inherited as a recessive trait and clinically may not be distinguished from dominantly inherited juvenile or developmental glaucoma caused by mutations in MYOC, FOXC1, PITX2, or PAX6. Establishing the molecular diagnosis for these patients will clarify the inheritance pattern making informed genetic counseling and risk assessment possible.

Mutations in both LTBP2 and CYP1B1 can cause autosomal recessive congenital glaucoma (onset before the age of 3). In the United States, the incidence of congenital glaucoma is estimated to be approximately $1 / 10,000$ (Fung et al. 2013). CYP1B1 mutations are found in $\sim 20 \%$ of patients, whereas LTBP2 mutations are very rare (Lim et al. 2013). Interestingly, in the United States the CYP1B1 mutation carrier frequency is three to five times higher than the incidence of congenital glaucoma would predict using Hardy-Weinberg distribution (Wiggs et al. 2014). The most prevalent CYP1B1 mutations in the United States carriers are missense alleles which may contribute to less severe early-onset disease (Wiggs et al. 2014). These results suggest that CYP1B1-related glaucoma may be more common than expected and that patients with juvenile and developmental glaucoma should be tested for CYP1B1 mutations, in addition to patients with severe congenital glaucoma.

\section{Presymptomatic Risk Assessment}

A family history of glaucoma is an important risk factor for disease development (Kooner et al. 2014), however, risk assessment based on family history alone is not precise. Genetic testing makes it possible to accurately identify mutation carriers with significantly increased risk for disease because of the high penetrance of mutations in early-onset glaucoma genes. The identification of individuals at risk for glaucoma makes it possible to begin treatment before the onset of irreversible optic nerve disease, thus providing the best opportunity to maintain useful sight.

\section{Surveillance and Treatment Plans}

For patients identified as early-onset glaucoma mutation carriers, defining the molecular diagnosis can impact therapeutic decisions. For ex- 
K.F. Allen et al.

ample, several MYOC mutations (Pro370Leu, Tyr437His) (Liu and Vollrath 2004) cause severe early-onset disease that usually requires surgery for treatment, whereas the most common MYOC mutation (GLN368X) can cause much milder disease that can be managed with topical medications (Allingham et al. 1998; Hogewind et al. 2010). Patients with less severe MYOC mutations can have earlier onset of disease if they also carry common modifying variants in COL15A1 and COL18A1 (Wiggs et al. 2013), suggesting that testing should be performed for both the primary mutations as well as modifier alleles.

Additionally, several early-onset glaucoma gene mutations can also cause systemic manifestations requiring further clinical attention. Patients with early-onset glaucoma related to Anridia caused by deletion of PAX6 may also be at risk for Wilm's tumor and should have a screening renal ultrasound (Hingorani et al. 2012). Patients with mutations in FOXC1 or PITX2 can also have cardiac abnormalities (Gripp et al. 2013; Wang et al. 2013) and hearing loss (D'haene et al. 2011).

\section{GENETIC TESTING FOR ADULT-ONSET GLAUCOMA}

Nine genes have been statistically associated with adult-onset glaucoma (disease onset after the age of 40) (Wang and Wiggs 2014). Although these associations are robust, genetic testing for adult-onset disease has several challenges. First, individual variants have a small effect on the overall disease risk and likely do not have a significant clinical impact unless they are in the context of other genetic and/or environmental risk factors. Second, the variants currently associated with adult onset disease are common and although the distribution among affected and unaffected individuals is significant, individually the sensitivity and specificity is not sufficient for a clinically useful test. For example, variants in the LOXL1 genomic region are significantly associated with pseudoexfoliation glaucoma and are found in $\sim 99 \%$ of affected patients, however, they are also found in $60 \%-80 \%$ of unaffected individuals (Fan et al.
2011). The development of gene panels, single nucleotide polymorphism (SNP) scores, and combinations of gene and environmental risk factors may yield useful gene-based tests for adult-onset glaucomas, however, these tests need to be validated in the clinical setting and should be correlated with clinical outcomes.

\section{CURRENT RECOMMENDATIONS FOR GLAUCOMA GENETIC TESTING}

Genetic testing is clinically useful for glaucoma patients with disease onset before age 40. Up to $20 \%$ of these patients will have a mutation in one of the genes currently known to cause earlyonset disease. This recommendation is consistent with the policy advocated by the Genetic Testing Task Force for the American Academy of Ophthalmology (Stone et al. 2012). If a mutation in the affected patient is found, further testing of members can be performed. In one study of Australian patients, testing of individuals with a family history of glaucoma and with onset up to age 50 was useful if the disease was advanced (Souzeau et al. 2013). Testing for patients with onset after age 50 is not currently useful clinically, but as more genetic and environmental risk factors are discovered comprehensive risk panel tests can be developed and validated.

\section{GENETIC TESTING FOR PRIMARY OPTIC NEUROPATHY}

Approximately $30 \%-50 \%$ of patients with primary optic atrophy will have mutations in OPA1 or mitochondrial DNA (LHON) (Fig. 3) (YuWai-Man et al. 2011). OPA1 mutations cause dominantly inherited optic atrophy that usually is bilateral and develops during the first or second decade of life. Three point mutations in the mitochondrial ND4 gene are responsible for $\sim 90 \%$ of LHON (Mackey et al. 1996). These mutations are maternally inherited and can have an asymmetric presentation. The mitochondrial DNA haplogroup appears to contribute to disease pathogenicity with haplogroup J of particular importance (Howell et al. 2003; Sadun et al. 2004). Rarely, mutations in OPA3 


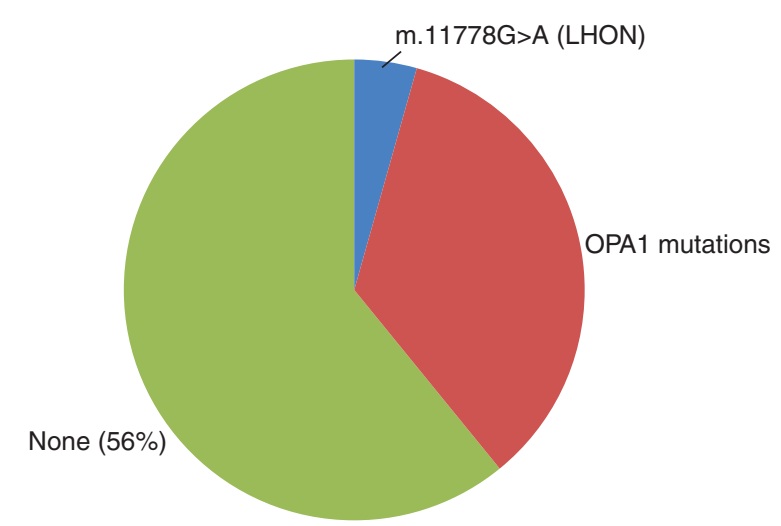

Figure 3. Distribution of mutation in mitochondrial DNA or OPA1 in a cohort of primary optic atrophy patients. Mutations in mitochondrial DNA or OPA1 are presented as a fraction of 64 patients evaluated through the genetic testing service at the Massachusetts Eye and Ear Infirmary. Fifty-six percent of patients with primary optic atrophy do not have a mutation in mitochondrial DNA, OPA1, or OPA3.

cause recessive optic atrophy that is commonly associated with cataracts and other neurological abnormalities (Ferré et al. 2009). Genetic testing for mutations in OPA1, OPA3, and mitochondrial DNA has important benefits for patients and family members including informed genetic counseling and risk assessment, avoidance of environmental exposures that may contribute to disease severity and identification of individuals who could be eligible for emerging genebased clinical therapy.

\section{Informed Genetic Counseling and Risk Assessment}

The clinical features of the primary optic neuropathies are sufficiently similar that clinical examination cannot reliably differentiate individuals with dominantly inherited disease caused by mutations in OPA1, maternally inherited disease caused by mitochondrial DNA mutations, or recessively inherited disease in patients with OPA3 mutations. By identifying the disease-causing mutation, genetic testing can accurately define the inheritance pattern and subsequent disease risk for family members. In addition, genetic testing can measure mitochondrial heteroplasmy, which is an important feature of mitochondrial disease pathogenicity (Wallace and Chalkia 2013).

\section{Avoidance of Environmental Risk Factors}

Studies have suggested that patients with mitochondrial DNA mutations causing LHON may have worse disease if exposed to excessive alcohol consumption, smoking, or have poor nutrition (Sadun et al. 2003; Kirkman et al. 2009). Patients carrying disease-causing mitochondrial DNA mutations may benefit from avoiding these risk factors. Additionally, there is some evidence to suggest that males with LHON may develop more severe disease than females owing to a putative protective effect of the $\mathrm{X}$ chromosome (Shankar et al. 2008).

\section{Identify Individuals with Mitochondrial DNA Mutations Who May be Eligible for Gene- Based Clinical Therapy}

Patients with selected mitochondrial DNA mutations may be eligible for gene-based therapies. A clinical trial evaluating the safety of adenoassociated virus (AAV) delivery of mitochondrial DNA to patients with Leber's hereditary optic atrophy is underway (Cwerman-Thibault et al. 2014; Koilkonda et al. 2014; Lam et al. 2014). Future gene-based therapies may be available for patients with mitochondrial DNA mutations as well as other genetic forms of primary optic atrophy. 
K.F. Allen et al.

\section{APPROACHES TO GENETIC TESTING FOR OPTIC ATROPHY (GLAUCOMA AND PRIMARY OPTIC NEUROPATHY)}

The group of genes currently known to cause early-onset glaucoma and primary optic atrophy could be tested by sequentially screening individual genes, however, because of the extensive phenotypic overlap among these conditions a panel test that simultaneously tests for mutations in all known genes is preferred. Because the primary open angle glaucoma normal-tension subgroup can have a clinical presentation similar to patients with primary optic atrophy, it is useful to include OPA1, OPA3, and the mitochondrial genome as well as the eight genes known to cause early-onset forms of glaucoma in the test. Panel testing can be accomplished using selective exon capture for all coding/ genomic regions of interest followed by next generation sequencing. A streamlined bioinformatic analysis is necessary to rapidly identify disease-causing mutations. Bioinformatic approaches are also required to identify the mitochondrial DNA heteroplasmy as well as the underlying mitochondrial DNA haplogroup that can impact the disease pathogenicity (Bannwarth et al. 2013). Another benefit of the gene panel approach is the opportunity to discover combinations of disease-causing mutations that may be overlooked using sequential screening.

Evaluation of copy number variation (CNVs, large genomic deletions and duplications) is necessary for comprehensive genetic testing. For the glaucoma and optic atrophy genes, genomic deletions and duplications, which would not be identified by DNA sequencing methods, are known to cause disease. In particular, both deletions and duplications of FOXC1 and OPA1 are relatively common disease-causing mutations (Chanda et al. 2008; Fuhrmann et al. 2009; Almind et al. 2011). Deletions and duplications may also impact regulatory elements that would not be targeted as part of the sequencing approaches (McBride et al. 2011; Volkmann et al. 2011). CNVs can be detected using a variety of approaches, including MLPA (Multiplex ligation-dependent probe amplification) (Redeker et al. 2008), array
CGH (array Comparative Genomic Hybridization) (Delahaye et al. 2012), and quantitative PCR (Wang et al. 2001).

\section{LIMITATIONS FOR GENETIC TESTING FOR OPTIC NEUROPATHIES (EARLY-ONSET GLAUCOMA AND PRIMARY OPTIC ATROPHY)}

The low clinical sensitivity is a major limitation of current genetic testing for early-onset glaucoma and primary optic atrophy $(20 \%$ and $50 \%$, respectively). The discovery of more disease-causing genes will improve the overall sensitivity of genetic testing for these disorders. Recent advances in genomic technologies, including whole exome and whole genome sequencing are making it possible to efficiently identify novel disease genes.

Another important limitation is the lack of clinical correlations and outcomes for disease-related mutations and variants. Early-onset glaucoma and primary optic atrophy can show considerable variable expressivity, both within and among affected families, which can complicate the clinical utility of the genetic diagnostic test. More research is needed to understand the molecular events that contribute to the spectrum of disease caused by early-onset glaucoma and primary optic atrophy genes.

For adult-onset glaucomas, clinical correlations and outcomes associated with specific genetic variants are also lacking. More complete risk panels (including both genetic and environmental factors) need to be developed and tested for disease risk prediction. Additionally, for adult-onset disease, specific risk factors could be correlated with selected clinical features such as IOP level, optic nerve disease susceptibility, and other glaucoma-related clinical features such as thin central corneal thickness.

\section{OPPORTUNITIES FOR NOVEL THERAPIES}

The identification of disease-causing genes is an important first step toward the development of gene-based therapies, which may involve gene replacement, gene inactivation or may use small molecules or other chemicals to modulate the mutation pathogenicity. Some opportunities 
for gene-based therapies for selected early-onset glaucoma and optic neuropathy genes are discussed in the following sections.

\section{MYOC}

Compelling evidence suggests that MYOC mutations cause a misfolded protein response that leads to endoplasmic reticulum stress and subsequent cellular dysfunction (Anholt and Carbone 2013). Interestingly, sodium phenyl butrate, a small molecule known to modulate the misfolded protein response can reduce IOP in a transgenic mouse with the MYOC mutation (Zode et al. 2011, 2012). This result supports the hypothesis that the misfolded protein response contributes to disease development and suggests that treatment approaches could involve reducing $M Y O C$ expression, inactivating the mutant mRNA using siRNA or other approaches such as CRISPR.

\section{CYP1B1}

Loss of CYP1B1 function results in early onset glaucoma. Patients with CYP1B1-related disease can show variable expressivity resulting in a range of disease phenotypes extending from severe congenital glaucoma to disease onset in later teenage years (Suri et al. 2009). In general, null alleles cause the most severe disease, whereas missense alleles can result in milder disease with later onset (López-Garrido et al. 2013). Phenotypically, CYP1B1-related glaucoma is caused, at least in part, by abnormal development of critical structures in the ocular anterior segment (Hollander et al. 2006). However, in patients with later onset disease ocular development may not be severely impaired and other processes related to reduced protein activity may be responsible for disease. For these patients, gene-based therapies could restore sufficient protein function that glaucoma development could be delayed and even eliminated.

\section{ND4 Leber's Hereditary Optic Neuropathy (LHON)}

More than $90 \%$ of patients affected by LHON have a point mutation in the mitochondrial
ND4 gene that codes for a critical subunit of respiratory chain complex I (Farrar et al. 2013). A gene-based treatment trial is currently in progress to test the safety and efficacy of delivery of a nuclear ND4 gene that could restore this critical protein to impaired mitochondria (Cwerman-Thibault et al. 2014; Lam et al. 2014). Mitochondrial defects may also be a factor in the development of adult-onset glaucoma (Jeoung et al. 2014) and the development of mitochondrial DNA therapies could potentially be beneficial for selected glaucoma patients. Additionally, gene-based therapies could be targeted in the future to other mitochondrial DNA mutations affecting other genes can also cause and/or contribute to optic neuropathies.

\section{Neuroprotective Therapies}

Therapies capable of protecting or repairing optic nerve function will provide the best opportunities to maintain and preserve sight in patients affected with inherited optic neuropathies. Genes associated with common forms of glaucoma, and especially the subgroup of primary open angle glaucoma with optic nerve degeneration without elevation of IOP (normaltension glaucoma) could be targets for genebased neuroprotective therapies. For example, $C D K N 2 B A S$ has been associated with primary open angle glaucoma (POAG), normal-tension glaucoma (NTG), and optic nerve CDR (Wiggs et al. 2012). This gene codes for an antisense RNA that regulates the expression of other proteins involved in cell cycle progression. The robust association between CDKN2BAS variants and optic nerve disease in glaucoma suggests that modulating CDKN2BAS expression, perhaps through a gene-based approach, could be neuroprotective.

Cell-based therapies, particularly the use of glial cells and mesenchymal stem cells, could protect against neurodegeneration and may also be capable of repairing optic nerve damage (Johnson and Martin 2013). Stem cells produce a variety of nerve growth factors that may have the ability to preserve and repair ganglion cell function. A clinical trial evaluating delivery of ciliary neurotrophic factor (CNTF), a 
K.F. Allen et al.

nerve growth factor that may have neuroprotective effects in glaucoma (Pease et al. 2009; Johnson et al. 2011), is currently ongoing (NCT014 08472). The results of these and other studies could lead to the development of novel therapies capable of preventing optic nerve degeneration in both glaucoma and primary optic atrophy.

\section{CONCLUDING REMARKS}

Glaucoma and primary optic atrophy are the most common inherited optic neuropathies encountered in a clinical setting and are important causes of blindness throughout the world. Genetic studies have revealed important genes responsible for these conditions and genetic testing for mutations in known genes can be beneficial. For early-onset glaucoma, genetic testing is most useful for patients with disease onset before age 40 . The overall clinical sensitivity of genetic testing for both early-onset glaucoma and primary optic atrophy will improve as new genes responsible for these conditions are discovered. For some optic nerve disorders, genetic information is defining approaches to novel gene-based therapies. Cell-based therapies and replacement of neurotrophic factors may also lead to novel neuroprotective treatment.

\section{REFERENCES}

${ }^{*}$ Reference is also in this subject collection.

Abu-Amero KK, Morales J, Aljasim LA, Edward DP. 2013. CYP1B1 mutations are a major contributor to juvenileonset open angle glaucoma in Saudi Arabia. Ophthalmic Genet doi: 10.3109/13816810.2013.841961.

Allingham RR, Wiggs JL, De La Paz MA, Vollrath D, Tallett DA, Broomer B, Jones KH, Del Bono EA, Kern J, Patterson K, et al. 1998. Gln368STOP myocilin mutation in families with late-onset primary open-angle glaucoma. Invest Ophthalmol Vis Sci 39: 2288-2295.

Almind GJ, Grønskov K, Milea D, Larsen M, BrøndumNielsen K, Ek J. 2011. Genomic deletions in OPA1 in Danish patients with autosomal dominant optic atrophy. BMC Med Genet 12: 49.

Anholt RR, Carbone MA. 2013. A molecular mechanism for glaucoma: Endoplasmic reticulum stress and the unfolded protein response. Trends Mol Med 19: 586-593.

Bannwarth S, Procaccio V, Lebre AS, Jardel C, Chaussenot A, Hoarau C, Maoulida H, Charrier N, Gai X, Xie HM, et al.
2013. Prevalence of rare mitochondrial DNA mutations in mitochondrial disorders. J Med Genet 50: 704-714.

Chanda B, Asai-Coakwell M, Ye M, Mungall AJ, Barrow M, Dobyns WB, Behesti H, Sowden JC, Carter NP, Walter $\mathrm{MA}$, et al. 2008. A novel mechanistic spectrum underlies glaucoma-associated chromosome 6p25 copy number variation. Hum Mol Genet 17: 3446-3458.

Cwerman-Thibault H, Augustin S, Ellouze S, Sahel JA, Corral-Debrinski M. 2014. Gene therapy for mitochondrial diseases: Leber hereditary optic neuropathy as the first candidate for a clinical trial. C R Biol 337: 193-206.

D'haene B, Meire F, Claerhout I, Kroes HY, Plomp A, Arens YH, de Ravel T, Casteels I, De Jaegere S, Hooghe S, et al. 2011. Expanding the spectrum of FOXC1 and PITX2 mutations and copy number changes in patients with anterior segment malformations. Invest Ophthalmol Vis Sci 52: 324-333.

Delahaye A, Bitoun P, Drunat S, Gérard-Blanluet M, Chassaing N, Toutain A, Verloes A, Gatelais F, Legendre M, Faivre L, et al. 2012. Genomic imbalances detected by array-CGH in patients with syndromal ocular developmental anomalies. Eur J Hum Genet 20: 527-533.

Fan BJ, Wiggs JL. 2010. Glaucoma: Genes, phenotypes, and new directions for therapy. J Clin Invest 120: 3064-3072.

Fan BJ, Pasquale LR, Rhee D, Li T, Haines JL, Wiggs JL. 2011. LOXL1 promoter haplotypes are associated with exfoliation syndrome in a U.S. Caucasian population. Invest Ophthalmol Vis Sci 52: 2372-2378.

Farrar GJ, Chadderton N, Kenna PF, Millington-Ward S. 2013. Mitochondrial disorders: Aetiologies, models systems, and candidate therapies. Trends Genet 29: 488-497.

Ferré M, Bonneau D, Milea D, Chevrollier A, Verny C, Dollfus H, Ayuso C, Defoort S, Vignal C, Zanlonghi X, et al 2009. Molecular screening of 980 cases of suspected hereditary optic neuropathy with a report on 77 novel OPA1 mutations. Hum Mutat 30: E692-E705.

Fuhrmann N, Alavi MV, Bitoun P, Woernle S, Auburger G, Leo-Kottler B, Yu-Wai-Man P, Chinnery P, Wissinger B. 2009. Genomic rearrangements in OPA1 are frequent in patients with autosomal dominant optic atrophy. J Med Genet 46: 136-144.

Fung DS, Roensch MA, Kooner KS, Cavanagh HD, Whitson JT. 2013. Epidemiology and characteristics of childhood glaucoma: Results from the Dallas Glaucoma Registry. Clin Ophthalmol 7: 1739-1746.

Gripp KW, Hopkins E, Jenny K, Thacker D, Salvin J. 2013. Cardiac anomalies in Axenfeld-Rieger syndrome due to a novel FOXC1 mutation. Am J Med Genet A 161A: 114119.

Hauser MA, Sena DF, Flor J, Walter J, Auguste J, LarocqueAbramson K, Graham F, Delbono E, Haines JL, PericakVance MA, et al. 2006. Distribution of optineurin sequence variations in an ethnically diverse population of low-tension glaucoma patients from the United States. $J$ Glaucoma 15: 358-363.

Hingorani M, Hanson I, van Heyningen V. 2012. Aniridia. Eur J Hum Genet 20: 1011-1017.

Hogewind BF, Mukhopadhyay A, Theelen T, Hollander AI, Hoyng CB. 2010. Variable clinical spectrum of the myocilin $G \ln 368 X$ mutation in a Dutch family with primary open angle glaucoma. Curr Eye Res 35: 31-36. 
Hollander DA, Sarfarazi M, Stoilov I, Wood IS, Fredrick DR, Alvarado JA. 2006. Genotype and phenotype correlations in congenital glaucoma: CYP1B1 mutations, goniodysgenesis, and clinical characteristics. Am J Ophthalmol 142: 993-1004.

Howell N, Herrnstadt C, Shults C, Mackey DA. 2003. Low penetrance of the 14484 LHON mutation when it arises in a non-haplogroup J mtDNA background. Am J Med Genet A 119A: 147-151.

Huang X, Li M, Guo X, Li S, Xiao X, Jia X, Liu X, Zhang Q. 2014. Mutation analysis of seven known glaucoma-associated genes in Chinese patients with glaucoma. Invest Ophthalmol Vis Sci 55: 3594-3602.

Jeoung JW, Seong MW, Park SS, Kim DM, Kim SH, Park KH. 2014. Mitochondrial DNA variant discovery in normal-tension glaucoma patients by next-generation sequencing. Invest Ophthalmol Vis Sci 55: 986-992.

Johnson TV, Martin KR. 2013. Cell transplantation approaches to retinal ganglion cell neuroprotection in glaucoma. Curr Opin Pharmacol 13: 78-82.

Johnson TV, Bull ND, Martin KR. 2011. Neurotrophic factor delivery as a protective treatment for glaucoma. Exp Eye Res 93: 196-203.

Kirkman MA, Yu-Wai-Man P, Korsten A, Leonhardt M, Dimitriadis K, De Coo IF, Klopstock T, Chinnery PF 2009. Gene-environment interactions in Leber hereditary optic neuropathy. Brain 132: 2317-2326.

Koilkonda RD, Yu H, Chou TH, Feuer WJ, Ruggeri M, Porciatti V, Tse D, Hauswirth WW, Chiodo V, Boye SL, et al. 2014. Safety and effects of the vector for the Leber hereditary optic neuropathy gene therapy clinical trial. JAMA Ophthalmol 132: 409-420.

Kooner K, Harrison M, Prasla Z, Albdour M, Adams-Huet B. 2014. Pediatric glaucoma suspects. Clin Ophthalmol 8: 1139-1145.

Lam BL, Feuer WJ, Schiffman JC, Porciatti V, Vandenbroucke R, Rosa PR, Gregori G, Guy J. 2014. Trial end points and natural history in patients with G11778A Leber hereditary optic neuropathy: Preparation for gene therapy clinical trial. JAMA Ophthalmol 132: 428-436.

Lim SH, Tran-Viet KN, Yanovitch TL, Freedman SF, Klemm T, Call W, Powell C, Ravichandran A, Metlapally R, Nading EB, et al. 2013. CYP1B1, MYOC, and LTBP2 mutations in primary congenital glaucoma patients in the United States. Am J Ophthalmol 155: 508-517.e5.

Liu Y, Vollrath D. 2004. Reversal of mutant myocilin nonsecretion and cell killing: Implications for glaucoma. Hum Mol Genet 13: 1193-1204.

López-Garrido MP, Medina-Trillo C, Morales-Fernandez L, Garcia-Feijoo J, Martínez-de-la-Casa JM, García-Antón M, Escribano J. 2013. Null CYP1B1 genotypes in primary congenital and nondominant juvenile glaucoma. Ophthalmology 120: 716-723.

Mackey DA, Oostra RJ, Rosenberg T, Nikoskelainen E, Bronte-Stewart J, Poulton J, Harding AE, Govan G, Bolhui PA, Norby S. 1996. Primary pathogenic mtDNA mutations in multigeneration pedigrees with Leber hereditary optic neuropathy. Am J Hum Genet 59: 481-485.

McBride DJ, Buckle A, van Heyningen V, Kleinjan DA. 2011. DNaseI hypersensitivity and ultraconservation reveal novel, interdependent long-range enhancers at the complex Pax6 cis-regulatory region. PLoS ONE 6: e28616.
Millá E, Mañé B, Duch S, Hernan I, Borràs E, Planas E, Dias Mde S, Carballo M, Gamundi MJ, Spanish Multicenter Glaucoma Group-Estudio Multicéntrico Español de Investigación Genética del Glaucoma, EMEIGG. 2013. Survey of familial glaucoma shows a high incidence of cytochrome P450, family 1, subfamily B, polypeptide 1 (CYP1B1) mutations in non-consanguineous congenital forms in a Spanish population. Mol Vis 19: 1707-1722.

Neuhann T, Rautenstrauss B. 2013. Genetic and phenotypic variability of optic neuropathies. Expert Rev Neurother 13: $357-367$.

Pease ME, Zack DJ, Berlinicke C, Bloom K, Cone F, Wang Y, Klein RL, Hauswirth WW, Quigley HA. 2009. Effect of CNTF on retinal ganglion cell survival in experimental glaucoma. Invest Ophthalmol Vis Sci 50: 2194-2200.

Redeker EJ, de Visser AS, Bergen AA, Mannens MM. 2008. Multiplex ligation-dependent probe amplification (MLPA) enhances the molecular diagnosis of aniridia and related disorders. Mol Vis 14: 836-840.

Ritch R, Darbro B, Menon G, Khanna CL, Solivan-Timpe F, Roos BR, Sarfarzi M, Kawase K, Yamamoto T, Robin AL, et al. 2014. TBK1 gene duplication and normal-tension glaucoma. JAMA Ophthalmol 132: 544-548.

Sadun AA, Carelli V, Salomao SR, Berezovsky A, Quiros PA, Sadun F, DeNegri AM, Andrade R, Moraes M, Passos A, et al. 2003. Extensive investigation of a large Brazilian pedigree of 11778/haplogroup J Leber hereditary optic neuropathy. Am J Ophthalmol 136: 231-238.

Sadun F, De Negri AM, Carelli V, Salomao SR, Berezovsky A, Andrade R, Moraes M, Passos A, Belfort R, da Rosa AB, et al. 2004. Ophthalmologic findings in a large pedigree of 11778/Haplogroup J Leber hereditary optic neuropathy. Am J Ophthalmol 137: 271-277.

Sena DF, Finzi S, Rodgers K, Del Bono E, Haines JL, Wiggs JL. 2004. Founder mutations of CYP1B1 gene in patients with congenital glaucoma from the United States and Brazil. J Med Genet 41: e6.

Shankar SP, Fingert JH, Carelli V, Valentino ML, King TM, Daiger SP, Salomao SR, Berezovsky A, Belfort R Jr, Braun TA, et al. 2008. Evidence for a novel X-linked modifier locus for Leber hereditary optic neuropathy. Ophthalmic Genet 29: 17-24.

Souzeau E, Burdon KP, Dubowsky A, Grist S, Usher B, Fitzgerald JT, Crawford A, Hewitt AW, Goldberg I, Mills RA, et al. 2013. Higher prevalence of myocilin mutations in advanced glaucoma in comparison with less advanced disease in an Australasian disease registry. Ophthalmology 120: $1135-1143$.

Stone EM, Aldave AJ, Drack AV, Maccumber MW, Sheffield VC, Traboulsi E, Weleber RG. 2012. Recommendations for genetic testing of inherited eye diseases: Report of the American Academy of Ophthalmology task force on genetic testing. Ophthalmology 119: 2408-2410.

Suri F, Yazdani S, Narooie-Nejhad M, Zargar SJ, Paylakhi SH, Zeinali S, Pakravan M, Elahi E. 2009. Variable expressivity and high penetrance of CYP1B1 mutations associated with primary congenital glaucoma. Ophthalmology 116: $2101-2109$

Volkmann BA, Zinkevich NS, Mustonen A, Schilter KF, Bosenko DV, Reis LM, Broeckel U, Link BA, Semina EV. 2011. Potential novel mechanism for Axenfeld-Rieger 
K.F. Allen et al.

syndrome: Deletion of a distant region containing regulatory elements of PITX2. Invest Ophthalmol Vis Sci 52: $1450-1459$.

Wallace DC, Chalkia D. 2013. Mitochondrial DNA genetics and the heteroplasmy conundrum in evolution and disease. Cold Spring Harb Perspect Med 3: a021220.

* Wang R, Wiggs JL. 2014. Common and rare genetic risk factors for glaucoma. Cold Spring Harb Perspect Biol 4: a017244.

Wang WH, McNatt LG, Shepard AR, Jacobson N, Nishimura DY, Stone EM, Sheffield VC, Clark AF. 2001. Optimal procedure for extracting RNA from human ocular tissues and expression profiling of the congenital glaucoma gene FOXC1 using quantitative RT-PCR. Mol Vis 7: 89-94.

Wang J, Xin YF, Xu WJ, Liu ZM, Qiu XB, Qu XK, Xu L, Li X, Yang YQ. 2013. Prevalence and spectrum of PITX2c mutations associated with congenital heart disease. DNA Cell Biol 32: 708-716.

Wiggs JL, Yaspan BL, Hauser MA, Kang JH, Allingham RR, Olson LM, Abdrabou W, Fan BJ, Wang DY, Brodeur W, et al. 2012. Common variants at 9p21 and 8q22 are associated with increased susceptibility to optic nerve degeneration in glaucoma. PLoS Genet 8: e1002654.
Wiggs JL, Howell GR, Linkroum K, Abdrabou W, Hodges E, Braine CE, Pasquale LR, Hannon GJ, Haines JL, John SW. 2013. Variations in COL15A1 and COL18A1 influence age of onset of primary open angle glaucoma. Clin Genet 84: $167-174$.

Wiggs JL, Langguth AM, Allen KF. 2014. Carrier Frequency of CYP1B1 Mutations in the United States. Trans Am Ophthalmol Soc (in press).

Yu-Wai-Man P, Shankar SP, Biousse V, Miller NR, Bean LJ, Coffee B, Hegde M, Newman NJ. 2011. Genetic screening for OPA 1 and OPA3 mutations in patients with suspected inherited optic neuropathies. Ophthalmology 118: 558563.

Zode GS, Kuehn MH, Nishimura DY, Searby CC, Mohan K, Grozdanic SD, Bugge K, Anderson MG, Clark AF, Stone EM, et al. 2011. Reduction of ER stress via a chemical chaperone prevents disease phenotypes in a mouse model of primary open angle glaucoma. J Clin Invest 121: 3542-3553.

Zode GS, Bugge KE, Mohan K, Grozdanic SD, Peters JC, Koehn DR, Anderson MG, Kardon RH, Stone EM, Sheffield VC. 2012. Topical ocular sodium 4-phenylbutyrate rescues glaucoma in a myocilin mouse model of primary open-angle glaucoma. Invest Ophthalmol Vis Sci 53: 1557-1565. 


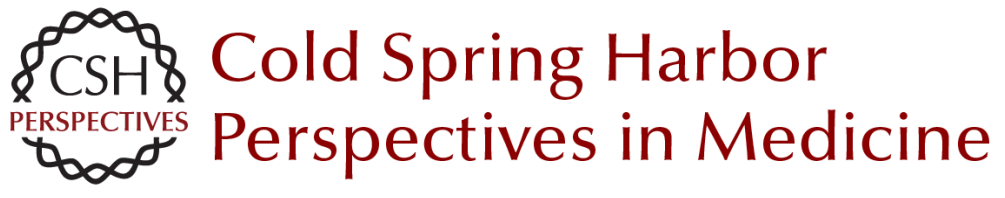

\section{Genetics of Primary Inherited Disorders of the Optic Nerve: Clinical Applications}

Keri F. Allen, Eric D. Gaier and Janey L. Wiggs

Cold Spring Harb Perspect Med 2015; doi: 10.1101/cshperspect.a017277

Subject Collection Retinal Disorders: Genetic Approaches to Diagnosis and Treatment

Trial by "Firsts": Clinical Trial Design and

Regulatory Considerations in the Development and Approval of the First AAV Gene Therapy

Product in the United States

Kathleen Z. Reape and Katherine A. High

Immunology of Retinitis Pigmentosa and Gene Therapy-Associated Uveitis

Paul Yang, Debarshi Mustafi and Kathryn L. Pepple

Developing New Vectors for Retinal Gene Therapy

Emilia A. Zin, Bilge E. Ozturk, Deniz Dalkara, et al.

Beyond the NEI-VFQ: Recent Experience in the Development and Utilization of Patient-Reported Outcomes for Inherited Retinal Diseases

Todd Durham, Judit Banhazi, Francesco Patalano, et al.

Electronic Retinal Prostheses

Daniel Palanker

Alternative RNA Splicing in the Retina: Insights and Perspectives

Casey J. Keuthan, Sadik Karma and Donald J. Zack

X-Linked Retinoschisis

Cristy A. Ku, Lisa W. Wei and Paul A. Sieving

A Systematic Review of Optogenetic Vision Restoration: History, Challenges, and New Inventions from Bench to Bedside

Antonia Stefanov and John G. Flannery
Lessons Learned from the Development of the

First FDA-Approved Gene Therapy Drug,

Voretigene Neparvovec-rzyl

Jean Bennett and Albert M. Maguire

Therapeutic Gene Editing in Inherited Retinal

Disorders Jinjie Ling, Laura A. Jenny, Ashley Zhou, et al.

Cell-Based Therapies: Strategies for Regeneration Marina Pavlou and Thomas A. Reh

The Importance of Natural History Studies in Inherited Retinal Diseases Allison Ayala, Janet Cheetham, Todd Durham, et al.

Photoreceptor Cell Replacement Using Pluripotent Stem Cells: Current Knowledge and Remaining Questions Christelle Monville, Olivier Goureau and Karim Ben M'Barek

iPSC-RPE in Retinal Degeneration: Recent Advancements and Future Perspectives Tadao Maeda and Masayo Takahashi

Retinal Degeneration Animal Models in BardetBiedl Syndrome and Related Ciliopathies Clarisse Delvallée and Hélène Dollfus

Mobility Testing and Other Performance-Based Assessments of Functional Vision in Patients with Inherited Retinal Disease Daniel Chung, Colas Authié and Laure Blouin

For additional articles in this collection, see http://perspectivesinmedicine.cshlp.org/cgi/collection/ 
For additional articles in this collection, see http://perspectivesinmedicine.cshlp.org/cgi/collection/ 